\title{
Depression and its Cure: A Drug Utilization Study from a Tertiary Care Centre
}

\section{of Western Nepal}

\author{
Banerjee $\mathrm{I}^{1}$, Roy B ${ }^{2}$, Banerjee $\mathrm{I}^{3}$, Sathian B ${ }^{4}$, Mondol M${ }^{5}$, Saha $\mathrm{A}^{6}$
}

${ }^{1}$ Lecturer, Department of Pharmacology, Manipal College of Medical Sciences, Pokhara, Nepal

${ }^{2}$ Assistant Professor, Department of Physiology, Manipal College of Medical Sciences, Pokhara, Nepal

${ }^{3}$ Junior Resident, MS General surgery, Kolkata Medical college, West Bengal, India

${ }^{4}$ Assistant Professor, Department of Community Medicine, Manipal College of Medical Sciences, Pokhara, Nepal

5 Lecturer, Department of Physiology, Manipal College of Medical Sciences, Pokhara, Nepal

${ }^{6}$ Professor \& HOD, Department of Pharmacology, Manipal College of Medical Sciences, Pokhara, Nepal

\section{Original Article}

\section{Corresponding Author: \\ Dr. Indrajit Banerjee MD \\ Lecturer, Department of Pharmacology, \\ Manipal College of Medical Sciences, Pokhara, Nepal \\ E-mail: indrajit18@gmail.com}

\section{Abstract}

\section{Background:}

According to WHO, it is estimated that major depression would be the second most leading cause of disability in the world by 2020. Drug utilization study is defined as study of the marketing, distribution, prescription and use of drugs in a society highlighting on the resulting medical, social and economic consequences. The main objective of this study was to find the utilization pattern of antidepressants prescribed in a tertiary care centre with major depression in hospitalized patients of Western Nepal.

\section{Methods:}

A hospital based observational study was done between $1^{\text {st }}$ October 2009 and $31^{\text {st }}$ March 2010 at Psychiatry Ward of Manipal Teaching Hospital, Nepal. Both qualitative and quantitative data was collected from bed side. The outcome variables were essential drug, generic and trade, treatment, groups of antidepressants and antidepressants used. The explanatory variables were age, gender, monthly income, employment of the patient. $Z$ test and logistic regression was used for the analysis. P-value $<0.05$ was considered to be statistically significant. This is the first study done to understand the utilization pattern of antidepressant drugs in hospitalized patients in Nepal.

\section{Results:}

Among the 240 psychiatric patients studied, 38 (15.8\%) cases were suffering from major depression. Male and female patients were $44.7 \%$ and $55.3 \%$ respectively, $95 \% \mathrm{Cl}$ $[28.9,60.5$ and $39.5,71.1]$. Depression was more common in housewives (42.1\%) followed by teachers $18.4 \%$ and students $10.5 \%$. Fluoxetine was the commonest antidepressants to be prescribed $42.1 \%$ followed by Amitriptyline $26.3 \%$, Trazodone $21.1 \%$ etc. Psychiatrists has a tendency of prescribing essential drugs if monthly income $<10000,1.063$ times as compared to monthly income $>10000,2.63$ times more in Hindus and 1.197 times more in Brahmins than any other ethnic groups. 9.179 times more tendency of prescribing antidepressants by trade names in case of unemployed patients as compared to employed patients in Nepal.

\section{Conclusion:}

According to the utilization pattern of antidepressants it was found that among the Selective serotonin reuptake inhibitors Fluoxetine was used relatively higher than conventional drugs like Tricyclic antidepressants, recommend that there is a trend of using Typical 
antidepressants drugs for depression rather than Newer antidepressants.

Keywords: Depression, Drug utilization study, Psychiatry, Nepal.

\section{Background}

Drug utilization study is defined as a study of the marketing, distribution, prescription and use of drugs in a society highlighting on the resulting medical, social and economic consequences. Medical aspects focus on the need to maintain a balance between the risk and the benefits of the drugs. The benefits are assessed on the basis of efficacy of the drugs in preventing, relieving and curing diseases or their symptoms and complications. Risks include the short term and long term adverse effects, special risk factors associated with genetics, disease and environment, nutrition, age, sex, pregnancy, lactation. Social aspects deal primary with the impact of drugs on the society, which includes the attitudes to drug and health, current trends in the treatment versus insistent use of conventional medicines. Drug abuse and their causes also are essential social components. Economic aspects reflect on the prices and the applicable heath benefits of a given drug. This includes the drug prices, imported drugs versus local products, costs of drug treatment as compared to non drug treatment. Current and future allocation of national resources to the drug $\&$ health budget is also an economic component ${ }^{1}$. Drug utilization research affords a baseline reference point about the effect of diverse interventions on prescribing concerning the drugs ${ }^{2,3}$.

According to WHO, it is estimated that unipolar major depression would be the second most leading cause of disability after ischaemic heart disease in the world by 2020 ; as of the year 1990 it was the fourth leading cause of disability worldwide ${ }^{4}$. From a study done in 2010 by Ball et al, in Srilanka, lifetime ever depression was reported in $6.6 \%$ of participants using the Composite International Diagnostic Interview $^{5}$. In major depression, a patient's mood is expressed as depressed, sad, hopeless, and discouraged. Symptoms of major depression are characterized by alteration of appetite or reduction or increase of weight, sleeplessness or hypersomnia, and psychomotor instability, reduced energy, feelings of guilt, obscurity of thoughts, frequent of death or suicidal thoughts, plans or attempts continues for most of the day, every day, for at least two weeks ${ }^{6}$. Holly et al. showed in 2003 that primary care physicians are conscious about depression is a prevalent state connected with considerable morbidity and mortality ${ }^{7}$.

Antidepressants are a type of antipsychotic drugs used for the treatment of depression is also called as thymoleptics and mood elevators ${ }^{8}$. It is commonly used in depression, anxiety disorders, chronic pain and enuresis. Atypical antidepressants like Buspirone, Venlafexine, Trazodone, are endorsed as better option for treating depression than conventional drugs as Selective serotonin reuptake inhibitors like Fluoxetine, Paroxetine, Citolapram and Tricyclic antidepressants like Imipramine, Desipramine, Clomipramine, Amitriptyline ${ }^{9}$.

Literature survey done by Jonathan et al in August 2008 for the period 1987-2009 showed that anxiolytic drug groups like benzodiazepines, azapirones, antihistamines, antidepressants, alpha-2-delta ligands, antipsychotics, and named drugs buspirone, venlafaxine, duloxetine, fluoxetine, escitalopram, olanzapine, paroxetine, pregabalin, quetiapine and risperidone, in addition to psychological therapies and cognitive-behavioral therapy, are commonly used treatment modalities ${ }^{10}$. Available data merely tells us that antidepressants are effective in moderate and severe depressive illness ${ }^{11}$. In a study done by Shankar et al. in 2001 in outpatient department of Psychiatry in Western Nepal showed that the frequency of use of antidepressants were $45.94 \%$, anxiolytics $19.41 \%$, antipsychotics $8.6 \%$ and antimanics $1.96 \%{ }^{12}$.

This is the first study undertaken in the utilization pattern of antidepressants drugs in hospitalized patients in Nepal. There is also no adequate information on the utilization pattern of antidepressants on Nepalese inhabitants. The main objective of the study was to find the utilization pattern of antidepressants prescribed in a tertiary care centre with major depression in hospitalized patients of Western Nepal. The specific objectives were to find out whether antidepressants were prescribed by generic or trade names, essential or nonessential, drug monotherapy or drugs and psychotherapy combined, commonest antidepressants used, socio demographic details and depression in Nepalese context.

\section{Material and Methods:}

\section{Study design and the participants:}

A hospital based observational study was done at Manipal Teaching Hospital, Pokhara, Nepal.

\section{Data collection:}

The study was carried out between $1^{\text {st }}$ October 2009 and $31^{\text {st }}$ March 2010, at Manipal Teaching Hospital in the Psychiatric ward. Both qualitative and quantitative data were collected. The quantitative data consisted of Socio demographic details like age ( $<40$ years and $>40$ years), sex (male and female), occupation (Housewife, teacher, laborer, shopkeeper, student, farmer, retired and others), religion (Hindu, Buddhist, Muslim), ethnicity (Brahmin, Chettri, Newar, Dalit and others), employment (employed and unemployed), monthly Income (<10000/month and $>10000$ /month, treatment (Drug monotherapy and drug and psychotherapy, based on essential drug list (essential or non essential), trade/generic, Commonest groups of antidepressants, commonest drug were used were collected. Anatomical Therapeutic Chemical Code was also used for different antidepressants prescribed. The qualitative research was undertaken by personal interview with the patient at the bedside in the psychiatry ward. 
The Anatomical Therapeutic Chemical (ATC Code) ${ }^{9}$

\begin{tabular}{|c|c|}
\hline Generic Name & ATC Code \\
\hline Fluoxetine & N06AB03 \\
\hline Amitriptyline & N06AA09 \\
\hline Imipramine & NO6AA02 \\
\hline Bupropion & N06AX12 \\
\hline
\end{tabular}

\section{Inclusion criteria:}

All the patients admitted in psychiatric ward with major depression from $1^{\text {st }}$ October 2009 to $31^{\text {st }}$ March 2010 were included in the study. 38 cases who were seriously ill with severe form of major depression were included in the study.

\section{Exclusion criteria:}

Out of 240 cases who were admitted in the Psychiatry inpatients only 202 cases were excluded from the study because we wanted to find the drug utilization pattern of antidepressants only. Additional cases those who were of Schizophrenia, Anxiety, Mania, Bipolar disorder, substance abuse, suicidal tendencies and mental retardation were excluded from the study. All the out-patients were also excluded from the study as we wanted to find the drug utilization study in those patients who are critically ill with major depression for which hospitalization was required.

\section{Sample size calculation:}

For $95 \%$ confidence interval and, significance level $\alpha=5 \%, P$ $=90 \%, Q=10 \%$, allowable error $=11 \%$, required sample size was 35. $P=$ percentage of antidepressants drugs used for the treatment of depression. In the pilot study done prior to the original study with 10 patients were admitted in the psychiatry ward with depression ${ }^{14}$.

\section{Outcome Variable:}

Essential drug list of Nepal, generic and trade, treatment (Drug therapy and psychotherapy), groups of antidepressants (newer and typical antidepressants), antidepressants (Fluoxetine, Amitriptyline, Imipramine, Trazodone, Bupropion).

\section{Explanatory variables:}

The demographic and psychiatric disorders were defined at individual level. Factors at individual level were Age, gender, monthly income, employment of the patient.

\section{Ethical committee approval:}

Prior to the study, ethical committee approval was taken from the ethical committee.

\section{Data management and statistical analysis:}

The data collected was analyzed using Excel 2003, R 2.8.0 Statistical Package for the Social Sciences (SPSS) for Windows Version 16.0 (SPSS Inc; Chicago, IL, USA) and EPI Info 3.5.1 Windows Version. The $Z$ test was used to observe the difference between different variables and strength of the relationship with logistic regression. $p<0.05$ is considered as statistically significant. We calculated odds ratios (OR) and their $95 \%$ confidence intervals $(95 \% \mathrm{Cl})$. $\mathrm{p}<$ 0.05 is considered as statistically significant ${ }^{15,16}$.

\section{Results}

\section{Psychiatric illness:}

Out of 240 cases admitted to the psychiatry ward, 130 were male $(54.2 \%), 95 \% \mathrm{Cl}[47.9,60.5]$ and others were female patients. Schizophrenia $36.3 \%$ was the major cause of hospitalization among psychiatric patients, followed by Depression $15.8 \%$ and anxiety $15.8 \%$, Bipolar disorders 8.3\%, Mania 3.8\% and all other psychiatric disorders like substance abuse, behavioral disturbances, suicidal tendencies and mental retardation 20\%. In Depression, out of 38 cases, male and female patients were $44.7 \%$ and $55.3 \%$ respectively, $95 \% \mathrm{Cl}[28.9,60.5$ and $39.5,71.1]$.

Table 1: Cross tabulation between Socio demographic factors, National Drug List of Nepal, Generic and Trade Names

\begin{tabular}{|c|c|c|c|c|c|}
\hline \multirow{2}{*}{\multicolumn{2}{|c|}{$\begin{array}{l}\text { Socio demographic } \\
\text { factors }\end{array}$}} & \multicolumn{2}{|c|}{$\begin{array}{c}\text { National Drug List of } \\
\text { Nepal }\end{array}$} & \multicolumn{2}{|c|}{ Generic/Trade } \\
\hline & & $\begin{array}{c}\text { Essential } \\
\text { Drugs }\end{array}$ & $\begin{array}{l}\text { Non- } \\
\text { essential } \\
\text { Drugs }\end{array}$ & Generic & Trade \\
\hline \multirow{4}{*}{ Age } & $>40$ yrs & $17(65.4)$ & $8(66.7)$ & $7(50)$ & $18(75)$ \\
\hline & $<40$ yrs & $9(34.6)$ & $4(33.3)$ & $7(50)$ & $6(25)$ \\
\hline & Total & $26(100)$ & $12(100)$ & $14(100)$ & $24(100)$ \\
\hline & P Value & $0.02 *$ & $0.08^{x}$ & $1^{x}$ & $0.0001^{\dagger}$ \\
\hline \multirow{4}{*}{ Gender } & Male & $13(50)$ & $4(33.3)$ & 8 (57.1) & $9(37.5)$ \\
\hline & Female & $13(50)$ & $8(66.7)$ & $6(42.9)$ & $15(62.5)$ \\
\hline & Total & $26(100)$ & $12(100)$ & $14(100)$ & $24(100)$ \\
\hline & P Value & $1^{x}$ & $0.08^{x}$ & $0.45^{\times}$ & $0.07^{\times}$ \\
\hline \multirow{4}{*}{ Employment } & Employed & $7(26.9)$ & $4(33.3)$ & $5(35.7)$ & $6(25)$ \\
\hline & Unemployed & 19(73.1) & $8(66.7)$ & $9(64.3)$ & $18(75)$ \\
\hline & Total & $26(100)$ & $12(100)$ & 14(100) & $24(100)$ \\
\hline & P Value & $0.0001^{\dagger}$ & $0.08^{x}$ & $0.12^{x}$ & $0.0001^{\dagger}$ \\
\hline \multirow{4}{*}{$\begin{array}{l}\text { Monthly } \\
\text { Income }\end{array}$} & $\begin{array}{l}>10000 / \\
\text { month }\end{array}$ & $6(23.1)$ & $4(33.3)$ & $1(7.1)$ & $9(37.5)$ \\
\hline & $\begin{array}{l}<10000 / \\
\text { month }\end{array}$ & $20(76.9)$ & $8(66.7)$ & 13(92.9) & $15(62.5)$ \\
\hline & Total & $26(100)$ & $12(100)$ & $14(100)$ & $24(100)$ \\
\hline & P Value & $0.0001^{\dagger}$ & $0.08^{x}$ & $0.0001^{\dagger}$ & $0.07^{x}$ \\
\hline
\end{tabular}

$+p<0.01$, statistically significant

$* p<0.05$, statistically significant

$\times p>0.05$, statistically not significant 
Table 1 depicts cross tabulation between socio demographic factors and national drug list of Nepal, generic and trade names. In case of patients older than 40 years $75 \%$ of the patient received antidepressants prescribed by trade names. If the patient was unemployed $73.1 \%$ and $75 \%$ received antidepressants from essential drug list of Nepal and by trade names. If the monthly income of the patients is $<10000,76.9 \%$ and $62.5 \%$ of the patients received antidepressants from essential drug list and by trade names. All the findings were found to be highly statically significant $(P=0.0001)$.

Table 2: Cross tabulation between Socio demographic factors, Treatment and Groups of Antidepressants

\begin{tabular}{|c|c|c|c|c|c|}
\hline \multirow{2}{*}{\multicolumn{2}{|c|}{ Socio demographic factors }} & \multicolumn{2}{|c|}{ Treatment } & \multicolumn{2}{|c|}{ Groups of } \\
\hline & & $\begin{array}{l}\text { Drugs and } \\
\text { Psycho } \\
\text { therapy } \\
\text { combined }\end{array}$ & $\begin{array}{c}\text { Drug } \\
\text { therapy }\end{array}$ & $\begin{array}{l}\text { Newer } \\
\text { Anti } \\
\text { depress } \\
\text { ants }\end{array}$ & $\begin{array}{l}\text { Typical Anti } \\
\text { depressants }\end{array}$ \\
\hline \multirow{4}{*}{ Age } & $>40$ yrs & $7(77.8)$ & $18(62.1)$ & $6(66.7)$ & 19 (65.5) \\
\hline & $<40$ yrs & $2(22.2)$ & $11(37.9)$ & $3(33.3)$ & $10(34.5)$ \\
\hline & Total & $9(100)$ & $29(100)$ & $9(100)$ & 29(100) \\
\hline & P Value & $0.0005^{\dagger}$ & $0.06^{x}$ & $0.13^{x}$ & $0.01 *$ \\
\hline \multirow{4}{*}{ Gender } & Male & $4(44.4)$ & $13(44.8)$ & $3(33.3)$ & $14(48.3)$ \\
\hline & Female & $5(55.6)$ & $16(55.2)$ & $6(66.7)$ & $15(51.7)$ \\
\hline & Total & $9(100)$ & $29(100)$ & $9(100)$ & $29(100)$ \\
\hline & P Value & $0.64^{x}$ & $0.43^{x}$ & $0.13^{x}$ & $0.793^{x}$ \\
\hline \multirow{4}{*}{ Employment } & Employed & $4(44.4)$ & $7(24.1)$ & $3(33.3)$ & $8(27.6)$ \\
\hline & Unemployed & $5(55.6)$ & $22(75.9)$ & $6(66.7)$ & $21(72.4)$ \\
\hline & Total & $9(100)$ & $29(100)$ & $9(100)$ & $29(100)$ \\
\hline & P Value & $0.64^{x}$ & $0.0001^{\dagger}$ & $0.13^{x}$ & $0.0001^{\dagger}$ \\
\hline \multirow[t]{4}{*}{$\begin{array}{l}\text { Monthly } \\
\text { Income }\end{array}$} & $\begin{array}{l}>10000 \\
\text { /month }\end{array}$ & 1(11.1) & $9(31)$ & $4(44.4)$ & $6(20.7)$ \\
\hline & $\begin{array}{l}<10000 \\
\text { /month }\end{array}$ & $8(88.9)$ & 20(69) & $5(55.6)$ & $23(79.3)$ \\
\hline & Total & $9(100)$ & 29(100) & $9(100)$ & 29(100) \\
\hline & P Value & $0.0001^{\dagger}$ & $0.002^{+}$ & $0.64^{x}$ & $0.0001^{+}$ \\
\hline
\end{tabular}

$+p<0.01$, statistically significant

$* p<0.05$, statistically significant

$\times p>0.05$, statistically not significant

Table 2 represents cross tabulation between Socio demographic factors, treatment and the groups of antidepressants prescribed. Drugs along with psychotherapy were used in $77.8 \%$ of the cases if the age of the patient is $>40$ years. Whereas in case of unemployed patients $75.9 \%$ and $72.4 \%$ received drug therapy only and typical antidepressants respectively. If the monthly income of the patients were less than $10000,88.9 \%$ received drug therapy along with psychotherapy and $79.3 \%$ of the patients received typical antidepressants. All the findings were found to be highly statically significant $(P=0.0001)$.

Figure 1: Occupations of patients suffering from Depression

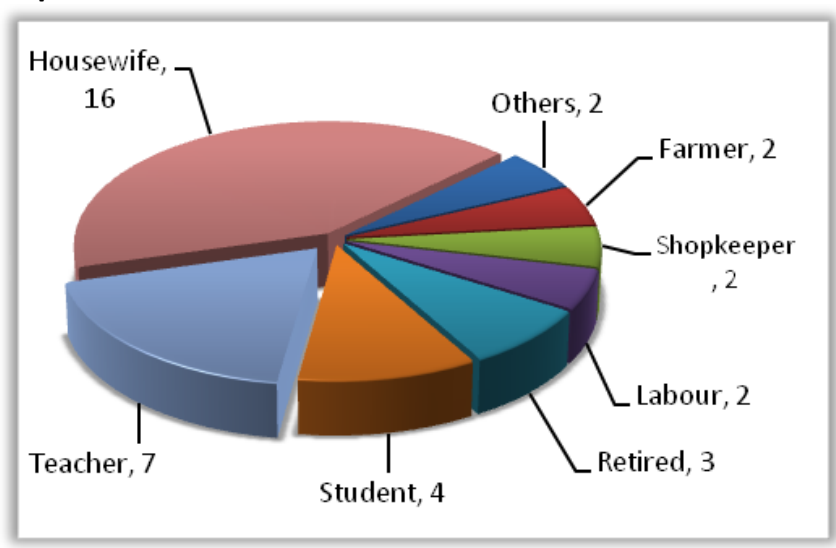

Figure 1 reveals that depression was more common in housewife $42.1 \%$ followed by teachers $18.4 \%$, students $10.5 \%$, retired $7.9 \%$ and farmer, shopkeeper and others were only $5.3 \%$ respectively.

Table 3: Cross tabulation between Socio demographic factors and Antidepressants prescribed

\begin{tabular}{|c|c|c|c|c|c|c|}
\hline \multirow{2}{*}{\multicolumn{2}{|c|}{$\begin{array}{c}\text { Socio } \\
\text { demographic } \\
\text { factors }\end{array}$}} & \multicolumn{5}{|c|}{ Antidepressants } \\
\hline & & \multirow{2}{*}{\begin{tabular}{|l|} 
Fluoxetine \\
$11(68.8)$
\end{tabular}} & \multirow{2}{*}{$\begin{array}{c}\text { Amitriptyline } \\
6(60)\end{array}$} & \multirow{2}{*}{$\begin{array}{c}\text { Imipramine } \\
2 \text { (66.7) }\end{array}$} & \multirow{2}{*}{$\begin{array}{l}\text { Trazodone } \\
5(62.5)\end{array}$} & \multirow{2}{*}{$\begin{array}{c}\text { Bupropion } \\
1(100)\end{array}$} \\
\hline \multirow{4}{*}{ Age } & $>40 \mathrm{yrs}$ & & & & & \\
\hline & $<40$ yrs & $5(31.3)$ & $4(40)$ & $1(33.3)$ & $3(37.5)$ & $0(0)$ \\
\hline & Total & $16(100)$ & 10(100) & $3(100)$ & $8(100)$ & $1(100)$ \\
\hline & P Value & $0.02 *$ & $0.36^{x}$ & $0.39^{x}$ & $0.30^{x}$ & - \\
\hline \multirow{4}{*}{ Gender } & Male & $9(56.2)$ & $4(40)$ & 1(33.3) & $2(25)$ & $1(100)$ \\
\hline & Female & $7(43.8)$ & $6(60)$ & $2(66.7)$ & $6(75)$ & $0(0)$ \\
\hline & Total & $16(100)$ & 10(100) & $3(100)$ & $8(100)$ & $24(100)$ \\
\hline & P Value & $0.48^{x}$ & $0.36^{x}$ & $0.39^{x}$ & $0.02 *$ & - \\
\hline \multirow{4}{*}{$\begin{array}{c}\text { Employ } \\
\text { ment }\end{array}$} & Employe & $5(31.2)$ & $2(20)$ & $1(33.3)$ & $2(25)$ & $1(100)$ \\
\hline & $\begin{array}{c}\text { Unemplo } \\
\text { yed }\end{array}$ & o 11(68.8) & $8(80)$ & $2(66.7)$ & $6(75)$ & $0(0)$ \\
\hline & Total & $16(100)$ & 10(100) & $3(100)$ & $8(100)$ & $1(100)$ \\
\hline & P Value & $0.02 *$ & $0.0001^{+}$ & $0.39^{x}$ & $0.02 *$ & - \\
\hline \multirow[t]{4}{*}{$\begin{array}{l}\text { Monthly } \\
\text { Income }\end{array}$} & $\begin{array}{l}>10000 \\
\text { /month }\end{array}$ & $3(18.8)$ & $3(30)$ & $0(0)$ & $4(50)$ & $0(0)$ \\
\hline & $\begin{array}{l}<10000 \\
\text { /month }\end{array}$ & 13(81.2) & $7(70)$ & $3(100)$ & $4(50)$ & $1(100)$ \\
\hline & Total & $16(100)$ & 10(100) & $3(100)$ & $8(100)$ & $1(100)$ \\
\hline & $P$ Value & $0.0001^{+}$ & $0.05^{x}$ & - & $1^{x}$ & - \\
\hline
\end{tabular}

$+p<0.01$, statistically significant

$* p<0.05$, statistically significant

$\times p>0.05$, statistically not significant

- $P$ value cannot calculate 
Table 3 reveals cross tabulation between Socio demographic factors and antidepressants prescribed. In about $68.8 \%$ Fluoxetine was prescribed in patient more than 40 years. In case of newer antidepressants like trazodone was more commonly prescribed in female patients $75 \%$ and in unemployed patients $75 \%$. Both cases it was statistically significant $(P=0.02)$. In case of $81.2 \%$ Fluoxetine was prescribed in patients with monthly income $<100000$ was found to be highly statistically significant ( $P=0.0001$ ).

Figure 2: Commonest Antidepressants prescribed

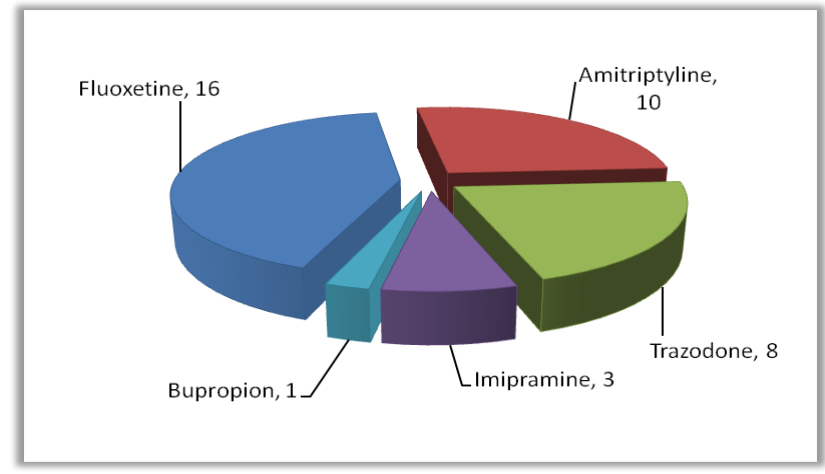

Figure 2 depicts that Fluoxetine (Selective serotonin reuptake inhibitors) was the commonest antidepressant to be prescribed $42.1 \%$ followed by Amitriptyline (Tricyclic antidepressants) $26.3 \%$, Trazodone (Newer antidepressants) 21.1\%, Imipramine (Tricyclic antidepressants) $7.9 \%$ and Bupropion (Newer antidepressants) 2.6\%.

Table 4: Logistic regression table of Essential drug list, Trade Names of drugs and socio demographic factors

\begin{tabular}{|c|c|c|}
\hline Socio & Essential Drug List & Trade names \\
\hline factors & $\begin{array}{l}\text { Odds ratio and } \\
\text { Confidence interval }\end{array}$ & $\begin{array}{l}\text { Odds ratio and } \\
\text { Confidence interval }\end{array}$ \\
\hline Age & $1.632(0.183-14.573)^{x}$ & $0.07(.007-.719)^{*}$ \\
\hline Gender & - & $0.951(0.060-15.167)^{x}$ \\
\hline Employment & - & $9.179(0.395-213.457)^{x}$ \\
\hline Monthly Income & $1.063(0.194-5.841)^{x}$ & $0.105(0.009-1.165)^{x}$ \\
\hline Religion & $2.630(0.254-27.187)^{\times}$ & $0.270(0.018-4.14)^{\times}$ \\
\hline Occupation & $0.755(0.43-1.324)^{x}$ & $1.137(0.720-1.796)^{x}$ \\
\hline Ethnicity & $1.197(0.615-2.330)^{x}$ & $1.378(0.628-3.024)^{x}$ \\
\hline
\end{tabular}

$* p<0.05$, statistically significant

$\times p>0.05$, statistically not significant

- $P$ value cannot calculate

Table 4 shows that the psychiatrist has a 1.632 times more tendency of prescribing essential medicines if the age of the patient is $>40$ years as compared to $<40$ years and in case of monthly income $<10000,1.063$ times as compared to monthly income $>10000,2.63$ times more in Hindus and
1.197 times more in Brahmins than any other ethnic groups. It is also seen that the psychiatrist has 9.179 times more tendency of prescribing antidepressants by trade names in case of unemployed patients as compared to employed patients, 1.137 times more in housewives and 1.378 times more in case of Brahmins.

Table 5: Logistic regression table of Drug monotherapy, Groups of drugs and socio demographic factors

\begin{tabular}{c|c|c|}
$\begin{array}{c}\text { Socio } \\
\text { demographic } \\
\text { factors }\end{array}$ & Drug monotherapy & Groups of drugs \\
\cline { 2 - 3 } Age & $\begin{array}{c}\text { Odds ratio and } \\
\text { Confidence interval }\end{array}$ & $\begin{array}{c}\text { Odds ratio and Confidence } \\
\text { interval }\end{array}$ \\
\hline Gender & $0.872(0.081-9.417)^{\times}$ & $1.182(0.110-12.651)^{\times}$ \\
\hline Employment & - & - \\
\hline Monthly Income & $0.244(0.024-2.463)^{\times}$ & $0.105(0.468-15.41)^{\times}$ \\
\hline Religion & $1.070(0.087-13.217)^{\times}$ & $0.912(0.088-9.442)^{\times}$ \\
\hline Occupation & $1.248(0.805-1.937)^{\times}$ & $0.944(0.552-1.614)^{\times}$ \\
\hline Ethnicity & $1.095(0.534-2.247)^{\times}$ & $1.5(0.72-3.125)^{\times}$ \\
\hline
\end{tabular}

$\times p>0.05$, statistically not significant

- $P$ value cannot calculate

Table 5 reveals that psychiatrists have a tendency to treat depression by drug therapy only 1.07 times more in Hindus as compared to any other religion, 1.248 times more in cases of housewives and 1.095 times more in case of Brahmins. As far as groups of drugs like typical and newer antidepressants are concerned, psychiatrists had a tendency of prescribing typical antidepressants 1.182 times more if the age of the patient is $>40$ years as compared to patients $<40$ years, 1.5 times more in Hindus than in any other religion.

\section{Discussion:}

\section{Prevalence of Depression}

Katon et al reported that the prevalence of depressive disorders in patients reporting to primary care is between $10-20 \%$, of which around $50 \%$ remain undiagnosed globally $^{17}$. Worldwide, major depression occurs in $2-4 \%$ of persons in community, $5-10 \%$ of primary care, and $10-14 \%$ in medical inpatients ${ }^{18}$. According to Vasiliadis et al, the prevalence of depression in United States were $8.7 \%$ and in Canada $8.2 \%{ }^{19}$. The prevalence of depression ranged between $7.8 \%$ and $9.0 \%$ in the three main Italian areas ${ }^{20}$. In the Southeast Asian country of Hong Kong, the 12-month general population prevalence of depressive disorders among adults was estimated at $8.4 \%{ }^{21}$. The prevalence of depression in South Indian population was $15.1 \%{ }^{22}$. The study done by Lamichhane on prevalence of mental illness in Nepal revealed that $4-6 \%$ of the total population of Nepal 
was suffering from Depression ${ }^{23}$. In our study, $15.8 \%$ of 240 cases admitted to the psychiatry ward were suffering from Depression.

\section{Socio-Demographic Details and Depression}

Out of 38 cases of Depression $44.7 \%$ of the cases were males and $55.3 \%$ of the cases were females. This finding is similar to a study done in Australia by Mant A et al which has showed that Psychiatric illness was more common in female patients ${ }^{24}$. Similar findings were also found in a study done by Hector M Gonzalez et al. on the use antidepressants among Asians in US in 2010 reveals that Depression is more prevalent in females than in male ${ }^{25}$.

Most of the patients with Depression were below 40 years of age $65.8 \%$, whereas only $34.2 \%$ of the patients were more than 40 years of age. Similar findings are also noted in a study which has shown that antipsychotics prescribed in youths have increased significantly ${ }^{26}$. Psychotropic drugs like Anxiolytics commonly prescribed in less than 40 years are also similar to our findings ${ }^{27}$. Similar findings are also found in a study done by Ramesh et al which has showed that somatic depression occurs in younger age group of patients. The total number of patients $(n=131)$ mean (SD) age, 32.53(12.50) years ${ }^{28}$.

In our study, most of the patients with Depression were Hindus $84.2 \%$, followed by Buddhist $13.2 \%$ and Muslim at 2.6\%. This could be due to the fact that Nepal is a Hindu country and we expect most of the patients are Hindus. Among the ethnic groups, $31.6 \%$ of the patients were Brahmin followed by Chettri 28.9, Dalit 15.8\%, Gurung 10.5\%, Newar 7.9\%. Pun, Magar, Lama and other ethnic groups were least in number constituting only $2.6 \%$. Depression was commonly seen in individuals with low monthly income. This finding is similar to a study done in Sweden by Lessen et al. which has showed that utilization of psychotropic drugs were more seen in individuals with low income ${ }^{29}$.

As far as occupation of the patient is concerned, depression is most commonly seen in Housewives $42.1 \%$, Teachers $18.4 \%$ followed by students $10.5 \%$ and retired persons 7.9\%. A study done by Boehlke has also showed that depression is common in housewives ${ }^{30}$.

\section{Qualitative Research}

Personal interview was the method used for Qualitative research in the patients, at the bed side, in the psychiatry ward to find out the cause of depression among housewives, teachers and students. We found that the major causes of depression in housewives were due to broken families, divorces, husbands not giving adequate time or husbands going to other countries for employment. Other causes of depression in housewives were described as their monotonous lifestyle and lack of entertainment. In case of teachers, the depression is due to their tedious lifestyle and repetitive daily routine for months to years. In case of students, it was found that they were unable to cope up with studies. According to the students from different branches, most of the professional courses like
MBBS, which is a four and half years course in Nepal, ${ }^{31-33}$ Engineering for four years, Human Biology for 4 years, BSc, BA, BBS, BPharm for three years which is quite long course and they remains unemployed at that period of time. Similar Qualitative research tool were used in housewife in 2011 by Banerjee et al ${ }^{27}$. Several other qualitative studies have been done worldwide related to depression ${ }^{34-36}$.

\section{Drug utilization of antidepressants}

\section{Drug therapy and psychotherapy}

In depressive patients, $76.3 \%$ received drug monotherapy compared to $23.7 \%$ drugs and psychotherapy. Psychotherapy was not used alone in any patient of depression. Most of the drugs were prescribed by trade names $63.2 \%$ whereas only $36.8 \%$ of the drugs were prescribed by generic name. This is similar to a study done in 2001 by PR Ravishankar on psychotropic drug utilization which has also shown that $71.3 \%$ of the drugs were prescribed by trade names ${ }^{12}$. It is also similar to a study done in 2011 by Banerjee et al. on utilization patterns of Anxiolytics drugs, which has also found that $78.9 \%$ of the Anxiolytics were prescribed by trade names ${ }^{27}$.

\section{Essential Drugs}

Essential drugs were used in $68.4 \%$ of the cases of depression. Nonessential drugs were used in $31.6 \%$, which is different from a study which has shown that only $29.48 \%$ were from essential drug list of Nepal ${ }^{12}$. Thus it was seen that there is a trend of prescribing drugs from essential drug list of Nepal by the psychiatrists. Drugs that are included from the essential drug list of Nepal are Fluoxetine and Amitriptyline ${ }^{37}$.

\section{Typical and Atypical antidepressants}

In case of antidepressants, most of the cases typical antidepressants were used $76.3 \%$, newer antidepressants were used only in $23.7 \%$ of cases. Among the typical antidepressants Selective serotonin reuptake inhibitors (SSRI's) like Fluoxetine were used in $42.1 \%$ of the cases. Tricyclic antidepressants (TCA) like amitriptyline were used in $26.3 \%$ followed by Imipramine $7.9 \%$. As far as newer antidepressants are concerned Trazodone were used in $21.1 \%$ and Bupropion were used in $2.6 \%$ of the cases of depression. So it was seen that psychiatrists had trend of prescribing typical antidepressants like serotonin reuptake inhibitors (SSRI's). This finding is dissimilar to a finding done by Raut in India which has found that among the antidepressants Tricyclic antidepressants were commonly used $54 \%$ followed by Selective Serotonin Reuptake Inhibitors were only $36 \%^{38}$. Our findings are similar to a study done on drug utilization of antidepressants in UK done from $1^{\text {st }}$ January 1992 to $31^{\text {st }}$ December 2001 in children and adolescents which showed that a total of 24976 patients received antidepressants. Among the antidepressants Selective serotonin reuptake inhibitors (SSRI's) Fluoxetine 9.89\%, was the commonest drug used. Among the Tricyclic antidepressants (TCA) Amitriptiline $5.72 \%$ followed by Imipramine $2.08 \%$ and Nortriptilline 
$0.52 \%$. Among the newer antidepressants Trazodone $4.68 \%$ was used. Out of which $55.7 \%$ received TCA followed by SSRI's $41.3 \%$ and other antidepressants $2.9 \%$. But the prevalence of the use of TCA has decreased by $30 \%$, whereas the use of SSRI's has increased by 10 folds in the last ten years $^{39}$.

\section{Advantages and Disadvantages of SSRIS}

Published evidence revealed that Tricyclic antidepressants might be suitable for depressed patients ${ }^{29}$ but Selective serotonin reuptake inhibitors are better tolerated. Selective serotonin reuptake inhibitors have very few autonomic adverse effects than Tricyclic antidepressants and less chance of arrhythmias and more safe in diabetes. But a lag period of 2-6 weeks is there before onset of maximum response is seen with most of the antidepressants ${ }^{37,40}$.

\section{Conclusion}

According to the drug utilization pattern of antidepressants it was found that Selective serotonin reuptake inhibitors were used in the treatment of depression in most of the cases $^{41}$. It was found that there is a trend of using Typical antidepressants drugs for depression rather than Newer antidepressants. Among the Selective serotonin reuptake inhibitors, psychiatrists have a relatively higher tendency of prescribing Fluoxetine than conventional drugs like Tricyclic antidepressants. Selective serotonin reuptake inhibitors are better tolerated, has very few autonomic adverse effects than Tricyclic antidepressants and less chances of arrhythmias.

\section{Limitation of the study}

Sample size of the study was the limitation of the study.

\section{Future scope of study}

A multi centered hospital based study with larger sample size required to find out the actual trend of using typical antidepressants and newer antidepressants drugs for depression in Nepal.

\section{Acknowledgments}

Authors are gratified to Dr. B. M. Nagpal, Dean and CEO, MCOMS, Nepal, Dr S. M. Banerjee, Orthopaedic surgeon, Kalyani, West Bengal, India, Dr Ramesh K. Professor and Head, Department of psychiatry, Pokhara, Nepal and the patients who took part in the study. We extend our heartfelt and cordial gratitude to $\mathrm{Dr}$ Akhilesh Chandra Jauhari, Professor, Department of Pharmacology, Manipal College of Medical sciences, Nepal for all proposition and cooperation in carrying out this study.

\section{Authors' contributions}

IB designed the study, deduced the data, drafted the manuscript, and revised it. BR planned the study with IB, acquired the data, conducted the data analysis, interpreted the data, and revised the manuscript. BS participated in statistical analysis, interpreted the data, and revised the manuscript. IB2, MM and AS critically revised the manuscript. All the authors approved the final document.

\section{Conflict of Interests}

The authors do not have any conflict of interest arising from the study.

\section{What this study adds}

By means of this study one is expected to acquire an idea concerning clinician's preference to antidepressants drugs in an actual clinical setup.

\section{References}

1. Uppal R. Drug utilization studies: a brief overview. Annual update in clinical pharmacology.1993:1:54-55.

2. Shankar PR. Drug utilization and rational use of medicines. Drug information Bulletin 2007; 5(3):6-8.

3. Dukes MNG, ed. Drug Utilization Studies: Methods and Uses. Copenhagen, WHO Regional Office for Europe, 1993 (WHO Regional Publications European Series No. 45)

4. Murray CJ, Lopez AD. Evidence-based health policy. Lessons from the Global Burden of Disease Study. Science 1996; 274:740-3.

5. Ball A Harriet, Siribaddana H Sisira, Kovas $Y$, Glozier N, McGuffin $P$, Sumathipala $A$, and Hotopf $M$. Epidemiology and symptomatology of depression in Sri Lanka: A cross-sectional population-based survey in Colombo District. J Affect Disord. 2010 June; 123(1-3): 188-196.

6. Mark A. Frye. Bipolar Disorder -A Focus on Depression. The New England Journal of Medicine. 2011; 364:51-9.

7. Holly A Swartz and Bruce I Rollman. Managing the global burden of depression: lessons from the developing world. World Psychiatry. 2003 October; 2(3): 162-163.

8. Ahuja N. Psychopharmacology. In: Ahuja S, eds. A Short Textbook of Psychiatry. 6th ed. New Delhi:Japee Brothers, 2009, pp 195.

9. Kang S, Lee N B, Chua C Hong, Rathi M, Fujii , S,Yang S, et al. Newer antidepressant drug use in East Asian psychiatric treatment settings: REAP (Research on East Asia Psychotropic Prescriptions) Study. $\mathrm{Br} J$ Clin Pharmacol. 2007 April; 63(4): 431-437.

10. Davidson JR, Feltner DE, Dugar A. Management of generalized anxiety disorder in primary care: identifying the challenges and unmet needs. Prim Care Companion J Clin Psychiatry 2010; 12(2).

11. Morris JB, Beck AT. The efficacy of antidepressant drugs. A review of research (1958-1972).Arch Gen Psychiatry 197; 30(5):667-74.

12. Shankar PR, Roy S. Patterns of prescription and drug use in psychiatry outpatient department in a teaching hospital in Western Nepal. The Internet Journal of Pharmacology 2002; 1(2). 
13. Nervous System. ATC/DDD Index. WHO collaborating centre for drug statistics methodology. [online] 2011 [cited 2011 July 19]. Available from: URL:http://www.whocc.no/ atc_ddd_index/?code $=\mathrm{N}$

14. Sathian B, Sreedharan J, Baboo NS, Sharan K, Abhilash E $\mathrm{S}$, Rajesh E. Relevance of Sample Size Determination in Medical Research. Nepal Journal of Epidemiology 2010; 1(1): 4-10.

15. Sathian B. Reporting dichotomous data using Logistic Regression in Medical Research: The scenario in developing countries. Nepal Journal of Epidemiology 2011;1(4):111-113.

16. Sathian B. Methodological Rigors in Medical Journals From Developing Countries: An Appraisal of the Scenario in Asia. Nepal Journal of Epidemiology 2011; 1(5): 141-43.

17. Katon W, Schulberg H. Epidemiology of depression in primary care. General Hospital Psychiatry. 1992;14(4): 237-247.

18. Katon W, Schulberg $H$. Epidemiology of depression in primary care. Gen Hosp Psychiatry. 1992 Jul;14(4):23747.

19. Vasiliadis H M, Lesage A, Adair C, Wang PS, Kessler RC. Do Canada and the United States Differ in Prevalence of Depression and Utilization of Services? Psychiatr Serv. 2007;58(1):63-71.

20. Berardi D, Leggieri G, Ceroni GB, Rucci P, Pezzoli A, Paltrinieri E, Grazian N, Ferrari G. Depression in primary care. A nationwide epidemiological survey. Fam Pract. 2002 Aug;19(4):397-400.

21. Weng Yee Chin, Cindy LK Lam, Samuel YS Wong, Yvonne YC Lo, Daniel YT Fong, Tai Pong Lam, Peter WH Lee, Josephine WS Wong, Billy CF Chiu, and Kit TY Chan. The epidemiology and natural history of depressive disorders in Hong Kong's primary care. BMC Fam Pract. 2011; 12: 129.

22. Subramani Poongothai, Rajendra Pradeepa, Anbhazhagan Ganesan, Viswanathan Mohan. Prevalence of Depression in a Large Urban South Indian Population - The Chennai Urban Rural Epidemiology Study (Cures - 70). PLoS One. 2009; 4(9): e7185.

23. Lamichhane N. Mental Health in Nepal. Virtual Doctor. [Online] 21 Aug 2008 [cited 2011 August 15]. Availablefrom:URL:http://www.pokharacity.com/virtual

doctor. php?subaction=showfull \&id=1219337345\& $\mathrm{archi}$ ve $=1245362037 \&$ start_from $=\& u c a t=74 \&$

24. Mant A, Lansbury G, Bridges-Webb C. Trends in psychotropic drug prescribing in Australia. Med J Aust1987; 146(4):208-10.

25. Hector M. Gonzalez, Wassim Tarraf, Brady T. West, Domin Chan, Patricia Y. Miranda and Fredrick T. Leong. Antidepressant Use among Asians in the United States.
Depression and Anxiety. 2010; 27(1): 46-55.

26. Chakos M, Lieberman J, Hoffman E, Bradford D, Sheitman B. Effectiveness of second-generation antipsychotics in patients with treatment-resistant schizophrenia: a review and meta-analysis of randomized trials. Am J Psychiatry 2001; 158(4):518-26.

27. Banerjee I, Roy B, Sathian B, Banerjee I, Kumar SS, Saha A. Medications for Anxiety: A Drug utilization study in Psychiatry Inpatients from a Tertiary Care Centre of Western Nepal. Nepal Journal of Epidemiology 2010; 1(4):119-25.

28. Ramesh MG, Sathian B, Shreevatsa BM, Bedanta R , Ramesh K, Budhachandra Y, Baboo NS. Gender Variation Of Somatic Symptoms Of Depression As Possible Indicators of Its Diagnosis And Severity. Journal of Clinical and Diagnostic Research [serial online] 2010 September [cited: 2010 October 14]; 4:3095-3099.

29. Lesen $E$, Anderrson $K$, Petzoid $M$, Carlsten A. Socioeconomic determinants of Psychotropic drug utilization among elderly: a national population based cross sectional study. BMC Public Health 2010; 10:118.

30. Boehlke J.Housewives \& Depression. [Online] Dec 2010[cited 2011 November 15]. Available from: URL:http://http://www.livestrong.com/article/138031housewives-depression/

31. Banerjee I, Jauhari CA, Johorey CA, Gyawali S, Saha A. Student's Accreditation of integrated Medical Education in Nepal. Asian Journal of Medical Sciences 2011;2 (1): 49-52.

32. Banerjee I, Jauhari A C, Bista D, Johorey A C, Roy B, Sathian B. Medical Students View about the Integrated MBBS Course: A Questionnaire Based Cross-sectional Survey from a Medical College of Kathmandu Valley. Nepal Journal of Epidemiology 2011;1(3): 95-100.

33. Roy B, Banerjee I, Sathian B, Mondal M, Kumar SS, Saha CG. Attitude of Basic Science Medical Students towards Medicine and Surgery Post Graduation: A Questionnaire based Cross-sectional Study from Western Region of Nepal. Nepal Journal of Epidemiology 2010; 1(4):12634.

34. Saver BG, Van-Nguyen V, Keppel G, Doescher MP. A qualitative study of depression in primary care: missed opportunities for diagnosis and education. J Am Board Fam Med. 2007;20(1):28-35.

35. Gask L, Ludman E, Schaefer J. Qualitative study of an intervention for depression among patients with diabetes: how can we optimize patient-professional interaction? Chronic Illn. 2006 Sep;2(3):231-42.

36. Dowrick C, Leydon GM, McBride A, Howe A, Burgess $H$, Clarke $P$, Maisey S, Kendrick T. Patients' and doctors' views on depression severity questionnaires incentivised in UK quality and outcomes framework: 
qualitative study. BMJ. 2009;338:b663. doi: 10.1136/bmj.b663.

37. Kafle KK, Prasad RR, Thapa BB. National List of Essential Medicine (forth revision draft). Nepalese National Formulary. $2^{\text {nd }}$ ed. Kathmandu, 2010, pp 443.

38. Raut P. Drug utilization pattern of Psychotropic drugs in Kasturba hospital [dissertation]. Kasturba Medical College: Manipal Univ., 2006.

39. M L Murray, C S de Vries, I C K Wong; A drug utilisation study of antidepressants in children and adolescents using the General Practice Research Database; Arch Dis Child 2004;89:1098-1102.

40. Bhattarai DD, Shrestha DA, Dixit H, AcharyaLI, KafleKK, Prasad RR, Thapa BB. National List of Essential Drugs. Nepalese National Formulary. 1sted. Kathmandu:Kanchan Printing Press,1997,pp 125-129.

41. Bae KY, Kim SW, Kim JM, Shin IS, Yoon JS, Jung SW, Lee MS, Yim HW, Jun TY. Antidepressant prescribing patterns in Korea: results from the clinical research center for depression study. Psychiatry Investig. 2011 ;8(3):234-44.

\section{Article Information}

\section{Article history}

\begin{tabular}{|l|l|}
\hline Received & 1 December2011 \\
\hline Received in revised form & 15 December 2011 \\
\hline Accepted & 25 December 2011 \\
\hline
\end{tabular}

